\title{
URBAN FORESTS IN THE CITY OF IVANOVO
}

(C) 2019

Borisova Elena Anatolyevna, doctor of biological sciences, professor, head of General Biology and Physiology Department

Ivanovo State University (Ivanovo, Russian Federation)

Abstract. The paper deals with the issue of urban forests in the city of Ivanovo which were saved on the territories of three parks. On the basis of special studies during 2012-2018 the main types of forests have been briefly described. The data on the forest flora are presented (338 species were recorded in the park named after the 1905 Revolution, 235 - in the park named after Stepanov, 217 - in the park «Kharinka»). The forests are dominated by typical forest species, 5 rare plants preserved (Epipactis palustris, Eryngium planum, Malaxis monophyllos, Ophioglossum vulgatum, Viola selkirkii), they are included into the regional Red Data book. There are also old trees of native species. Planting trees, creating lawns and flower beds greatly enriched their flora. In general, the composition and structure of forests are disturbed, weed and ruderal alien species (groups of Acer negundo, Amelanchier spicata, Cerasus vulgaris, Cotoneaster lucidus, Fraxinus pennsylvanica, Malus domestica, Sambucus racemosa, etc.) are noted. Some species (Cerasus maximowiczii, Crataegus monogyna, Padus pensylvanica, Parthenocissus inserta, Phellodendron amurense, Thladiantha dubia, Telekia speciosa) belong to the rare invasive plants of the Ivanovo Region. The parks possess the status of specially protected natural areas, they are of great environmental, ecological, scientific and aesthetic value. As a result of the territory zoning of these valuable forest areas they have been assigned to the reserves with a strict protection regime.

Keywords: urban forests; green areas of cities; urban parks; specially protected natural areas (SPNA); composition of forest flora; forest structure; rare plant species; regional Red Data book; alien and invasive plant species; zoning; problems of forest protection; city of Ivanovo.

\section{АНАЛИЗ ОСОБЕННОСТЕЙ НАКОПЛЕНИЯ И РАСПРЕДЕЛЕНИЯ ТЯЖЁЛЫХ МЕТАЛЛОВ В ПОЧВЕННОМ ПОКРОВЕ ГОРОДОВ САМАРА И СЫЗРАНЬ}

(C) 2019

\author{
Бугров Сергей Вячеславович, аспирант кафедры экологии, ботаники и охраны природы \\ Макарова Юлия Владимировна, кандидат биологических наук, \\ доцент кафедры экологии, ботаники и охраны природы \\ Прохорова Наталья Владимировна, доктор биологических наук, \\ профессор кафедры экологии, ботаники и охраны природы \\ Платонов Игорь Артемьевич, доктор технических наук, профессор, заведующий кафедрой химии \\ Горюнов Максим Глебович, кандидат химических наук, инженер кафедры химии \\ Самарский наџиональный исследовательский университет имени академика С.П. Королёва \\ (2. Самара, Российская Федераџия)
}

Аннотация. В статье представлены результаты статистического анализа данных накопления и распределения ряда тяжёлых металлов $(\mathrm{Cr}, \mathrm{Ni}, \mathrm{Cu}, \mathrm{Pb}, \mathrm{Cd}, \mathrm{Zn})$ в почвах городов Самара и Сызрань Самарской области, проведенного с использованием рангового коэффициента корреляции Спирмена, рангового дисперсионного анализа Краскела-Уоллиса и метода главных компонент. Показано, что почвы г. Самары в большей степени подвержены накоплению $\mathrm{Cr}, \mathrm{Ni}, \mathrm{Cu}$ и $\mathrm{Cd}$, чем г. Сызрани. Более высокие валовые концентрации металлов наблюдаются в функциональных зонах городов, характеризующихся повышенной техногенной нагрузкой, - вблизи промышленных предприятий и вдоль железных дорог. Закреплению металлов в верхнем гумусовом горизонте способствует органическое вещество почвы. Исключение составляет Рb, валовая концентрация которого не зависит от типа функциональной зоны и содержания органического углерода. Дисперсионный ранговый анализ Краскела-Уоллиса позволил установить наличие статистически значимой связи между механическим состав почвы и валовыми концентрациями $\mathrm{Cr}$ и $\mathrm{Ni}$, содержание которых увеличивается в почвах более тяжёлого механического состава. Согласно методу главных компонент, определяющее влияние на содержание и характер распределения тяжёлых металлов в почвенном покрове городов оказывают естественные и техногенные источники металлов; почвенные характеристики (механический состав, актуальная кислотность почвенного раствора, содержание органического углерода) и интенсивность воздействия источников поступления тяжелых металлов играют менее значимую роль.

Ключевые слова: почва; механический состав почвы; актуальная кислотность почвенного раствора; содержание органического углерода; гумусность; тяжёлые металлы; валовое содержание тяжёлых металлов; кларк химического элемента; методы статистического анализа; коэффициент корреляции Спирмена; ранговый дисперсионный анализ Краскела-Уоллиса; метод главных компонент; город Самара; город Сызрань; Самарская область. 
Бугров С.В., Макарова Ю.В., Прохорова Н.В., Платонов И.А., Горюнов М.Г.

Химическое загрязнение окружающей среды является одной из главных проблем современного мира. Хозяйственная деятельность человечества приводит к значительным изменениям интенсивности и направленности существующих потоков миграции химических элементов, к формированию новых потоков миграции элементов и геохимических барьеров $[1$, с. $30 ; 2$, с. 14$]$. При этом скорость изменения химического состава природной среды настолько высокая, что сложившиеся экосистемы не успевают перестроиться и деградируют [3, с. 8-9]. Данный процесс происходит повсеместно на земном шаре, однако он наиболее характерен для территорий, испытывающих повышенный уровень антропогенной нагрузки, - для городов. К числу наиболее распространённых и опасных городских поллютантов относят тяжёлые металлы $[4$, с. $5 ; 5$, с. 9].

Основным естественным источником тяжёлых металлов для компонентов биосферы являются почвообразующие горные породы, на продуктах выветривания которых сформировался почвенный покров [6, с. 5]. Присутствуя в горных породах и почвах преимущественно в низких концентрациях, тяжёлые металлы активно вовлекаются в биологический круговорот веществ в качестве микро- и ультрамикроэлементов и обеспечивают выполнение многих функций в живых организмах. Избыточное накопление тяжелых металлов токсично для живых организмов: оно замедляет их рост и развитие, угнетает иммунную систему, ускоряет процессы старения, способствует возникновению тератогенных и мутагенных изменений [5, с. 17-38; 7, с. 5-7; 8, с. 9-37].

Городская среда оказывается в большей мере подвержена загрязнению тяжелыми металлами в связи с наличием развитой автотранспортной инфраструктуры, а также размещением на урбанизированных территориях (или в непосредственной близости от них) предприятий чёрной и цветной металлургии, машиностроительных и нефтеперерабатывающих заводов $[9$, с. $164-176 ; 10$, с. $4 ; 11]$. Анализ почвенного покрова позволяет определить степень загрязнения различных районов урбанизированных территорий и оценить особенности миграции и аккумуляции тяжёлых металлов в условиях города.

\section{Объекты и методы исследования}

В качестве объектов исследования были выбраны почвы двух городов Самарской области - Сызрани и Самары, отличающихся по уровню антропогенной нагрузки. Самара - это административный центр области, крупный промышленный город с населением более 1 млн чел. На территории Самары располагается несколько десятков крупных и средних промышленных предприятий (литейный завод $3 \mathrm{AO}$ «Завод специального машиностроения «Маяк», АО «Завод «Самарский подшипник», ООО «Средневолжский Машиностроительный Завод», ООО «СамЛит», АО «Самарский трансформатор» и др.) [12]. Сызрань - третий по величине город Самарской области с населением 174 тыс. чел. и несколькими крупными предприятиями (АО «Тяжмаш», АО «Кардан», ООО «Лидер-Тюнинг», ООО «Сельмаш», ОАО «Сызранский нефтеперерабатывающий завод», «Сызранская ТЭЦ») [13].

В каждом городе были выделены 5 функциональных зон: парковая зона, жилая зона, автодорога, промышленная зона, железная дорога. Отбор поч- венных проб в перечисленных зонах проводили в 2018 г. из верхнего гумусового горизонта (0-10 см) согласно действующему стандарту $[14$, с. $3-4]$. На территории г. Самары было отобрано 20 проб, в г. Сызрани - 29 проб. У почвенных проб изучали: механический состав «мокрым» методом [15, с. $32-$ 33], актуальную кислотность почвенного раствора потенциометрическим методом на иономере «И-500» («НПО Аквилон», Россия) [16, с. 69], содержание органического углерода по методу Тюрина [16, с. 217220], валовое содержание $\mathrm{Cr}, \mathrm{Ni}, \mathrm{Cu}, \mathrm{Pb}, \mathrm{Cd}$ и $\mathrm{Zn}$ методом спектрометрии с индуктивно-связанной плазмой (экстрагент $5 \mathrm{M} \mathrm{HNO}_{3}$ ) [17] на оптико-эмиссионном спектрометре «PlasmaQuant ${ }^{\circledR} \mathrm{PQ} 9000 »$ («Analytik Jena

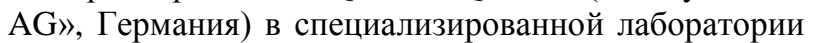
кафедры химии Самарского университета. Выбор анализируемых элементов связан с их постоянным присутствием в техногенных потоках загрязнения городов Самара и Сызрань.

С целью выявления закономерностей распределения тяжёлых металлов в условиях городов, полученные данные были проанализированы методами статистического анализа с использованием программы STATISTICA 10. Статистическая обработка результатов анализа включала в себя построение матрицы корреляций на основе коэффициента ранговой корреляции Спирмена, ранговый дисперсионный анализ Краскела-Уоллиса и анализ методом главных компонент.

\section{Результаты исследования и их обсуждение}

Одним из главных условий применения параметрических многомерных методов статистического анализа данных является нормальность распределения случайной выборки. В реальных условиях при малом объёме выборки и активном техногенном поступлении элементов данное требование может нарушаться. Поэтому для определения нормальности распределения полученных сведений о содержании тяжёлых металлов был взят один из наиболее эффективных критериев проверки нормальности - критерий Шапиро-Уилка. Согласно результатам расчета, закон нормального распределения не соблюдается для значений концентраций анализируемых металлов, вследствие чего статистический анализ данных проводился с помощью методов, нечувствительных к характеру распределения.

Важным критерием оценки степени загрязнённости почвы химическими элементами является отношение фактической концентрации элемента к его кларку. Согласно А.П. Виноградову [9, с. 208-213], кларки тяжёлых металлов в земной коре следующие: $\mathrm{Cr}-83,0$ мг/кг; Ni - 58,0 мг/кг; $\mathrm{Cu}-47,0$ мг/кг; $\mathrm{Pb}-$ 16,0 мг/кг; Cd - 0,13 мг/кг; Zn - 83,0 мг/кг. Кларки концентрации изучаемых тяжёлых металлов в почве приведены в табл. 1.

Из табл. 1 следует, что концентрации $\mathrm{Cr}, \mathrm{Ni}$ и $\mathrm{Cu}$ редко превышают их кларковые значения, что может быть связано с низким уровнем поступления этих химических элементов в результате антропогенной деятельности. Превышение кларковых значений для $\mathrm{Pb}$ и $\mathrm{Cd}$ наблюдается примерно в половине всех изученных почвенных проб. Высокое содержание Zn в почвах встречается не так часто, но превышение кларкового уровня может быть очень сильным. 
Для определения взаимосвязей между содержанием в почве валовых форм тяжёлых металлов, почвенными характеристиками (механический состав, актуальная кислотность почвенного раствора - $\mathrm{pH}$, содержание органического углерода - Сорг.) и уровнем антропогенной нагрузки (функциональная зона города, в которой осуществлялся отбор почвенных проб) был вычислен коэффициент ранговой корреляции Спирмена (табл. 2). Преимущество данного коэффициента заключается в том, что он позволяет обрабатывать ненормально распределённые данные, измеренные как в интервальной, так и в порядковой шкалах.

Анализ результатов расчёта коэффициента Спирмена (табл. 2) позволяет говорить о том, что основными факторами, определяющими содержание металлов в почвах, могут быть механический состав почв, содержание органического углерода и уровень антропогенной нагрузки, связанный со способом использования городской территории. Органическое вещество почвы выступает в качестве адсорбента элементов, задерживая их в верхнем почвенном горизонте. Также более тяжёлый гранулометрический состав способствует накоплению тяжёлых металлов за счёт увеличения удельной поверхности почвы [18, c. 54]. Корреляция между типом функциональной зоны и концентрацией металлов объясняется, вероятно, повышенным уровнем поступления поллютантов вследствие усиления техногенной нагрузки. Стоит также отметить высокие значения корреляции между металлами, что может свидетельствовать об общности источника их происхождения и подверженности одним и тем же закономерностям распределения.

Ранговый дисперсионный анализ КраскелаУоллиса является непараметрическим аналогом одномерного дисперсионного анализа и позволяет определить, действительно ли имеются различия в значениях переменной между выделяемыми группами. В рамках настоящего исследования дисперсионный анализ применялся с целью установления значимости различий между валовыми концентрациями тяжёлых металлов в городских почвах, механическим составом, кислотно-основными свойствами и гумусностью почв, типом городской функциональной зоны и местом отбора (г. Самара или г. Сызрань). Результаты анализа приведены в табл. 3.

Исходя из полученных данных, можно установить, что особенности кислотно-основных свойств почвы не проявляют существенного воздействия на накопление тяжёлых металлов (p > 0,05). Содержание органического углерода, напротив, оказывает статистически значимое влияние на накопление почти всех изучаемых металлов в почве (за исключением $\mathrm{Pb}$ ). Наибольшие концентрации элементов (наибольшие значения средних рангов) наблюдаются при содержании углерода от 3,1 до $4 \%$ и от 4,1 до $5 \%$. Этот эффект согласуется с результатами других исследований $[19$, с. $285 ; 20]$ и подтверждает результаты корреляционного анализа (табл. 2). Утяжеление механического состава почвенного покрова также способствует накоплению тяжёлых металлов, однако в условиях городов Самара и Сызрань данный эффект проявляется на статистически значимом уровне $(p<0,05)$ лишь для $\mathrm{Cr}$ и $\mathrm{Ni}$. Особенности накопления тяжёлых металлов в зависимости от уровня антропогенной нагрузки выражены достаточно сильно. Наиболее высокие концентрации металлов наблюдаются в промышленной зоне и участках, прилегающих к железнодорожному полотну, наименьшие концентрации характерны для парков и селитебных территорий. В то же время распределение $\mathrm{Pb}$ не связано со способом использования территории. И наконец, различия в накоплении тяжёлых металлов между Самарой и Сызранью обнаруживаются для $\mathrm{Cr}$, $\mathrm{Ni}, \mathrm{Cu}$ и $\mathrm{Cd}$. Почвенный покров г. Самары в большей степени подвержен накоплению этих металлов, что, возможно, связано с наличием большого количества крупных предприятий и более развитой дорожной инфраструктурой или местными особенностями почв. При этом содержание $\mathrm{Pb}$ и $\mathrm{Zn}$ между населёнными пунктами существенно не различается.

Метод главных компонент позволяет выявить в многомерном пространстве значений факторы, оказывающие влияние на разброс показателей, и сократить их количество, объединив несколько однонаправленных факторов в один - главную компоненту. Метод главных компонент также может служить основой для классификации данных по характеру действия на них различных факторов. Анализ распределения $\mathrm{Cr}, \mathrm{Ni}, \mathrm{Cu}, \mathrm{Pb}, \mathrm{Cd}$ и $\mathrm{Zn}$, а также кислотности почв и содержания органического углерода (C) позволил обнаружить 8 факторов (компонент), три из которых имеют наибольшее значение (собственное значение больше 1) и объясняют $81 \%$ общей дисперсии. Действие факторов визуализировано на рисунке 1 .

Фактор 1 объясняет 48,12\% общей дисперсии и, таким образом, является наиболее значительным. Его воздействие проявляется в увеличении концентраций тяжёлых металлов и содержания органического углерода. Также фактор 1 оказывает незначительное влияние на $\mathrm{pH}$, сдвигая реакцию среды в щелочную сторону. Возможно, фактор 1 представляет собой совокупность естественных и техногенных источников поступления элементов в почвенную среду. Фактор 2 объясняет $16,87 \%$ разброса значений и по характеру воздействия на элементы позволяет разделить их на две группы. Фактор 2 способствует накоплению $\mathrm{Cd}$, $\mathrm{Pb}$ и $\mathrm{Zn}$ и препятствует увеличению концентраций $\mathrm{Cr}, \mathrm{Ni}$ и $\mathrm{Cu}$. Исходя из результатов дисперсионного анализа Краскела-Уоллиса (табл. 3), можно предположить, что фактор 2 связан с механическим составом почвы, так как нижняя группа элементов $(\mathrm{Ni}, \mathrm{Cr})$ накапливается в тяжёлых почвах. Фактор 2 может быть связан и с особенностями поступления тяжёлых металлов. Из табл. 1 видно, что для верхней группы элементов $(\mathrm{Pb}, \mathrm{Cd}, \mathrm{Zn})$ чаще всего наблюдаются превышения кларковых значений. И всё же нельзя однозначно установить, чем объясняется данный фактор, поэтому, вероятно, он представляет собой интегральное воздействие сразу нескольких параметров. Фактор 3 не оказывает существенного воздействия на большинство тяжёлых металлов (за исключением $\mathrm{Zn})$ и влияет лишь на изменение $\mathrm{pH}$ и гумусность. Следовательно, данный фактор может быть связан с поступлением в почвенную среду веществ, изменяющих её кислотно-основные свойства: строительного мусора, противогололёдных реагентов и др. 
Бугров С.В., Макарова Ю.В., Прохорова Н.В., Платонов И.А., Горюнов М.Г.

таблица 1 - Статистические показатели кларков концентрации тяжёлых металлов, полученные для почв городов Самара и Сызрань

\begin{tabular}{|l|c|c|c|c|c|c|}
\hline \multicolumn{1}{|c|}{ Параметр } & \multicolumn{5}{c|}{ Химический элемент } \\
\cline { 2 - 8 } & $\mathrm{Cr}$ & $\mathrm{Ni}$ & $\mathrm{Cu}$ & $\mathrm{Pb}$ & $\mathrm{Cd}$ & $\mathrm{Zn}$ \\
\hline Максимальное значение & 1,65 & 3,73 & 3,31 & 11,02 & 11,80 & 21,79 \\
\hline Минимальное значение & 0,04 & 0,05 & 0,04 & 0,22 & 0,73 & 0,13 \\
\hline Среднее значение & 0,31 & 0,54 & 0,64 & 1,91 & 2,58 & 1,52 \\
\hline Медиана & 0,25 & 0,40 & 0,46 & 1,25 & 2,15 & 0,64 \\
\hline Количество превышений кларка, ед. (\%) & $2(4,0)$ & $4(8,1)$ & $7(14,2)$ & $22(44,9)$ & $34(69,3)$ & $13(26,5)$ \\
\hline
\end{tabular}

Таблица 2 - Показатели коэффициента ранговой корреляции Спирмена, полученные для почв городов Самара и Сызрань

\begin{tabular}{|c|c|c|c|c|c|c|c|c|c|c|c|}
\hline \multirow{2}{*}{\multicolumn{2}{|c|}{ Параметр }} & \multirow{2}{*}{$\begin{array}{l}\text { Мех. } \\
\text { состав }\end{array}$} & \multirow{2}{*}{$\mathrm{pH}$} & \multirow{2}{*}{ С орг. } & \multirow{2}{*}{$\begin{array}{c}\text { Функциональ- } \\
\text { ная зона }\end{array}$} & \multicolumn{6}{|c|}{ Валовое содержание элемента } \\
\hline & & & & & & $\mathrm{Cr}$ & $\mathrm{Ni}$ & $\mathrm{Cu}$ & $\mathrm{Pb}$ & $\mathrm{Cd}$ & $\mathrm{Zn}$ \\
\hline \multicolumn{2}{|l|}{ Мех. состав } & 1,00 & 0,00 & 0,24 & $-0,05$ & $0,38 *$ & $0,47 *$ & 0,23 & $-0,21$ & 0,15 & $-0,13$ \\
\hline \multicolumn{2}{|l|}{$\mathrm{pH}$} & 0,00 & 1,00 & $-0,38 *$ & $0,29 *$ & 0,16 & 0,16 & 0,12 & $-0,05$ & $-0,07$ & $-0,13$ \\
\hline \multicolumn{2}{|l|}{ С орг. } & 0,24 & $-0,38 *$ & 1,00 & 0,07 & $0,47 *$ & $0,47 *$ & $0,40 *$ & 0,26 & $0,61 *$ & $0,35^{*}$ \\
\hline \multicolumn{2}{|c|}{ Функциональная зона } & $-0,05$ & $0,29 *$ & 0,07 & 1,00 & $0,37 *$ & $0,30 *$ & $0,39 *$ & 0,19 & $0,30 *$ & 0,25 \\
\hline \multirow{6}{*}{$\begin{array}{l}\text { Валовое со- } \\
\text { держание } \\
\text { элемента }\end{array}$} & $\mathrm{Cr}$ & $0,38 *$ & 0,16 & $0,47 *$ & $0,37 *$ & 1,00 & $0,93 *$ & $0,80 *$ & 0,24 & $0,75^{*}$ & $0,32 *$ \\
\hline & $\mathrm{Ni}$ & $0,47 *$ & 0,16 & $0,47 *$ & $0,30 *$ & $0,93 *$ & 1,00 & $0,80^{*}$ & 0,22 & $0,72 *$ & $0,28^{*}$ \\
\hline & $\mathrm{Cu}$ & 0,23 & 0,12 & $0,40 *$ & $0,39 *$ & $0,80 *$ & $0,80 *$ & 1,00 & $0,55^{*}$ & $0,87 *$ & $0,64^{*}$ \\
\hline & $\mathrm{Pb}$ & $-0,21$ & $-0,05$ & 0,26 & 0,19 & 0,24 & 0,22 & $0,55^{*}$ & 1,00 & $0,63 *$ & $0,78^{*}$ \\
\hline & $\mathrm{Cd}$ & 0,15 & $-0,07$ & $0,61 *$ & $0,30^{*}$ & $0,75^{*}$ & $0,72 *$ & $0,87 *$ & $0,63^{*}$ & 1,00 & $0,71^{*}$ \\
\hline & $\mathrm{Zn}$ & $-0,13$ & $-0,13$ & $0,35^{*}$ & 0,25 & $0,32 *$ & $0,28 *$ & $0,64 *$ & $0,78^{*}$ & $0,71 *$ & 1,00 \\
\hline
\end{tabular}

Примечание. Знаком «*» отмечены статистически значимые показатели $(p<0,05)$.

Таблица 3 - Результаты рангового дисперсионного анализа Краскела-Уоллиса, проведенного в отношении почв с различными физико-химическими характеристиками и уровнем антропогенной нагрузки в г. Самара и г. Сызрань

\begin{tabular}{|c|c|c|c|c|c|c|c|}
\hline \multicolumn{2}{|c|}{ Градации оцениваемого параметра } & $\mathrm{Cr}$ & $\mathrm{Ni}$ & $\mathrm{Cu}$ & $\mathrm{Pb}$ & $\mathrm{Cd}$ & $\mathrm{Zn}$ \\
\hline \multicolumn{8}{|c|}{ Механический состав } \\
\hline \multirow{6}{*}{$\begin{array}{l}\text { Средние } \\
\text { ранги }\end{array}$} & Песок & 21,81 & 80,18 & 24,90 & 30,00 & 24,18 & 28,36 \\
\hline & Супесь & 18,00 & 17,22 & 18,63 & 25,86 & 22,18 & 25,81 \\
\hline & Лёгкий суглинок & 17,90 & 18,75 & 17,80 & 20,90 & 18,75 & 20,10 \\
\hline & Средний суглинок & 41,50 & 41,16 & 39,16 & 27,08 & 36,91 & 30,66 \\
\hline & Тяжёлый суглинок & 32,66 & 34,33 & 33,16 & 30,00 & 31,83 & 28,50 \\
\hline & Глина & 32,60 & 34,60 & 26,80 & 11,80 & 23,00 & 14,60 \\
\hline \multicolumn{2}{|c|}{ Критерий Краскела-Уоллиса (Н) } & 16,797 & 18,917 & 12,658 & 7,340 & 8,023 & 5,774 \\
\hline \multicolumn{2}{|c|}{ р-уровень } & 0,0049 & 0,0020 & 0,268 & 0,1965 & 0,1549 & 0,3288 \\
\hline \multicolumn{8}{|c|}{$\mathrm{pH}$} \\
\hline \multirow{4}{*}{$\begin{array}{l}\text { Средние } \\
\text { ранги }\end{array}$} & $<7,3$ & 15,40 & 14,70 & 19,00 & 20,90 & 15,70 & 22,40 \\
\hline & $7,31-7,7$ & 18,57 & 17,85 & 23,57 & 34,07 & 30,71 & 34,00 \\
\hline & $7,71-8,1$ & 28,40 & 28,35 & 24,90 & 20,80 & 25,41 & 22,73 \\
\hline & $>8,1$ & 23,71 & 25,14 & 31,14 & 28,28 & 24,14 & 27,57 \\
\hline \multicolumn{2}{|c|}{ Критерий Краскела-Уоллиса (Н) } & 5,429 & 5,997 & 2,246 & 4,314 & 3,289 & 3,924 \\
\hline \multicolumn{2}{|c|}{ р-уровень } & 0,1429 & 0,1117 & 0,5228 & 0,2294 & 0,3491 & 0,2698 \\
\hline \multicolumn{8}{|c|}{ Содержание органического углерода, \% } \\
\hline \multirow{5}{*}{$\begin{array}{l}\text { Средние } \\
\text { ранги }\end{array}$} & $<1$ & 8,00 & 10,50 & 7,33 & 20,00 & 6,83 & 4,66 \\
\hline & $1,1-2$ & 18,23 & 18,11 & 21,76 & 21,61 & 18,30 & 25,61 \\
\hline & $2,1-3$ & 25,72 & 25,27 & 23,44 & 22,63 & 23,02 & 21,66 \\
\hline & $3,1-4$ & 34,70 & 34,90 & 33,60 & 30,00 & 35,20 & 30,60 \\
\hline & $4,1-5$ & 30,80 & 30,80 & 32,40 & 35,30 & 40,00 & 36,40 \\
\hline \multicolumn{2}{|c|}{ Критерий Краскела-Уоллиса (Н) } & 12,642 & 11,739 & 10,427 & 5,411 & 18,657 & 11,797 \\
\hline \multicolumn{2}{|c|}{ р-уровень } & 0,0132 & 0,0194 & 0,0338 & 0,247 & 0,0009 & 0,0189 \\
\hline \multicolumn{8}{|c|}{ Функциональные зоны } \\
\hline \multirow{5}{*}{$\begin{array}{l}\text { Средние } \\
\text { ранги }\end{array}$} & Парковая зона & 8,00 & 10,50 & 7,33 & 20,00 & 6,83 & 4,66 \\
\hline & Жилая зона & 18,23 & 18,11 & 21,76 & 21,61 & 18,30 & 25,61 \\
\hline & Автодорога & 25,72 & 25,27 & 23,44 & 22,63 & 23,02 & 21,66 \\
\hline & Промышленная зона & 35,11 & 34,44 & 34,11 & 30,77 & 34,55 & 29,66 \\
\hline & Железная дорога & 30,83 & 32,16 & 31,83 & 33,25 & 40,16 & 36,83 \\
\hline \multicolumn{2}{|c|}{ Критерий Краскела-Уоллиса (Н) } & 12,716 & 11,55 & 10,495 & 5,060 & 18,83 & 12,153 \\
\hline \multicolumn{2}{|c|}{ р-уровень } & 0,0127 & 0,0210 & 0,0329 & 0,2812 & 0,0008 & 0,0162 \\
\hline \multicolumn{8}{|c|}{ ённый пунк } \\
\hline \multirow{2}{*}{$\begin{array}{l}\text { Средние } \\
\text { ранги }\end{array}$} & Самара & 32,90 & 34,70 & 35,00 & 27,32 & 32,25 & 28,20 \\
\hline & Сызрань & 19,55 & 18,31 & 18,103 & 23,39 & 20,00 & 22,79 \\
\hline \multicolumn{2}{|c|}{ Критерий Краскела-Уоллиса (Н) } & 10,329 & 15,574 & 16,551 & 0,894 & 8,703 & 1,694 \\
\hline \multicolumn{2}{|l|}{ р-уровень } & 0,0013 & 0,0001 & 0,0000 & 0,3442 & 0,0032 & 0,1930 \\
\hline
\end{tabular}


Воздействие факторов 1 и 2

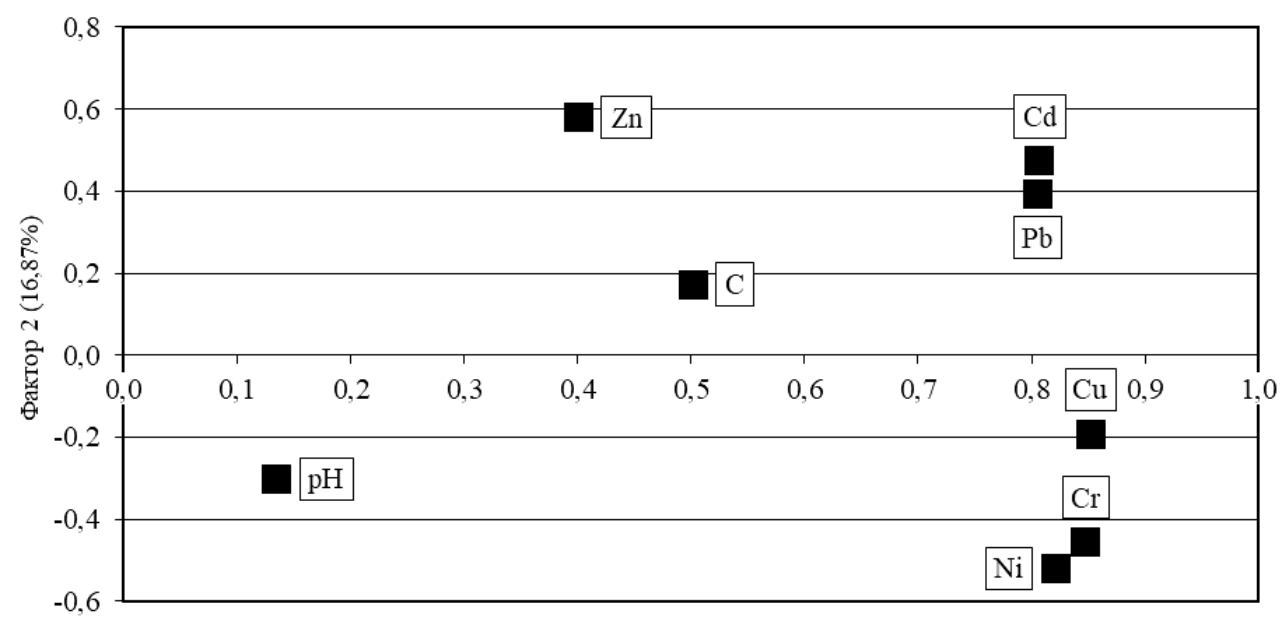

Фактор $1(48,12 \%)$

Воздействие факторов 2 и 3

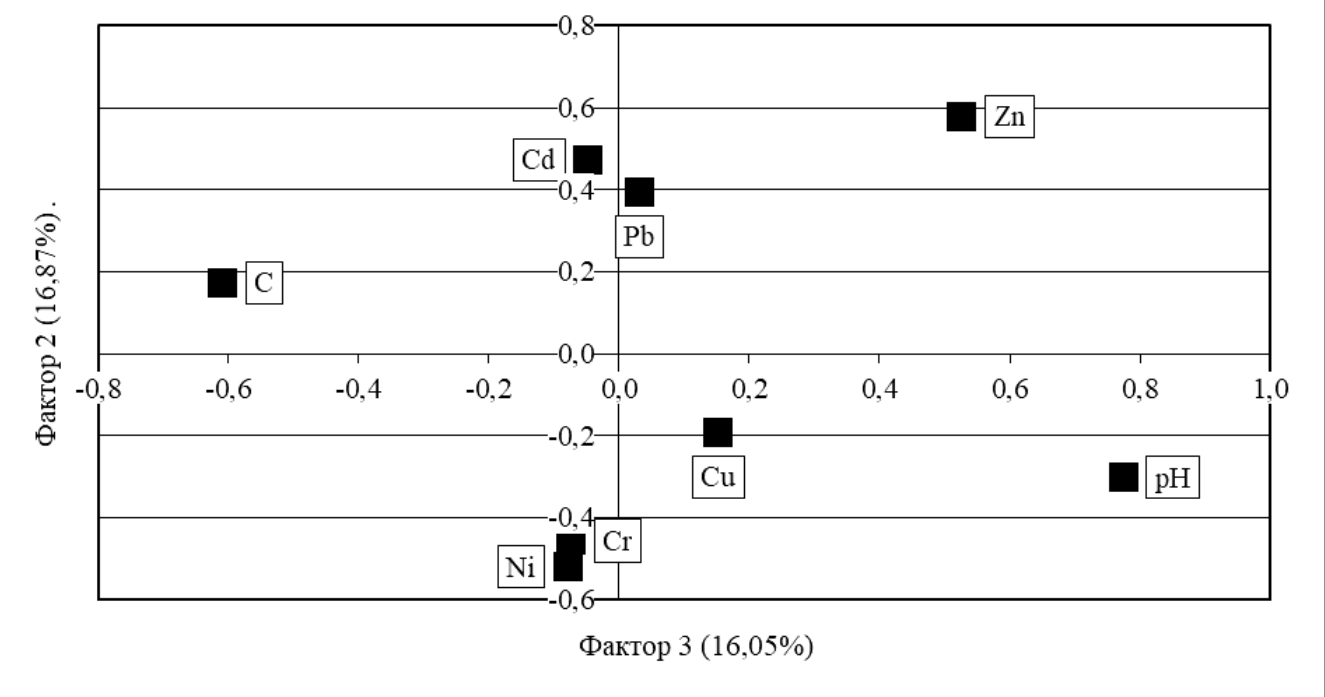

Рисунок 1 - Визуальное представление воздействия факторов

на разброс концентраций тяжёлых металлов в изучаемых почвах

\section{Заключение}

Статистический анализ данных является мощным инструментом исследования, позволяющим выявить скрытые и неочевидные закономерности. В результате статистической обработки данных о концентрациях тяжёлых металлов в почвах городов Самара и Сызрань было установлено, что высокое содержание $\mathrm{Cr}, \mathrm{Ni}, \mathrm{Cu}, \mathrm{Cd}$ и $\mathrm{Zn}$ сопутствует высокому (для городских условий) содержанию гумуса (от 3 до 5\%). Также на распределение металлов влияет уровень антропогенной нагрузки, приходящейся на данную территорию. Так, повышенные концентрации элементов характерны для промышленных зон и участков вдоль железной дороги, в то время как парковые и жилые зоны отличаются меньшим содержанием металлов. Исключение составляет $\mathrm{Pb}$, концентрация которого не зависит от типа функциональной зоны и содержания органического углерода. Возможно, такое поведение элемента связано с широким распространением в недавнем прошлом антидетонационных присадок автомобильного топлива, одним из действующих веществ которых являлся тетраэтилсвинец.

Дисперсионный ранговый анализ Краскела-Уоллиса также позволил установить наличие статистически значимой связи между механическим составом почвы и валовыми концентрациями $\mathrm{Cr}$ и $\mathrm{Ni}$, содержание которых увеличивается в более тяжёлых почвах. Анализ зависимостей распределения тяжёлых металлов между Самарой и Сызранью позволяет говорить о том, что для почв г. Самары в большей степени характерно накопление $\mathrm{Cr}, \mathrm{Ni}, \mathrm{Cu}$ и $\mathrm{Cd}$, что может объясняться как особенностями местных почв, так и более высокой техногенной нагрузкой на окружающую среду в условиях крупного города.

По результатам анализа данных методом главных компонент можно сделать предположение, что разброс значений элементов объясняется в большей степени наличием естественных и техногенных источников поступления, в то время как почвенные параметры и интенсивность воздействия источников поступления играют менее значимую роль в распределении тяжёлых металлов. 
Бугров С.В., Макарова Ю.В., Прохорова Н.В., Платонов И.А., Горюнов М.Г.

Список литературы:

1. Алексеенко В.А., Алексеенко А.В. Химические элементы в геохимических системах. Кларки почв селитебных территорий: монография. Ростов-наДону: Издательство Южного федерального университета, 2013. 380 с.

2. Алексеенко В.А., Алексеенко Л.П. Геохимические барьеры: учеб. пособие. М.: Логос, 2003. 144 с.

3. Мотузова Г.В., Карпова Е.А. Химическое загрязнение биосферы и его экологические последствия: учебник. М.: Изд-во Московского ун-та, 2013. $304 \mathrm{c}$.

4. Водяницкий Ю.Н., Ладонин Д.В., Савичев А.Т. Загрязнение почв тяжёлыми металлами. М.: Московский государственный университет им. М.В. Ломоносова, 2012. 305 c.

5. Давыдова С.Л., Тагасов В.И. Тяжелые металлы как супертоксиканты XXI века: учеб. пособие. М.: Изд-во РУДН, 2002. 140 с.

6. Прохорова Н.В., Матвеев Н.М., Павловский В.А. Аккумуляция тяжелых металлов дикорастущими и культурными растениями в лесостепном и степном Поволжье. Самара: Издательство «Самарский университет», 1998. $131 \mathrm{c.}$

7. Водяницкий Ю.Н. Тяжёлые и сверхтяжёлые металлы и металлоиды в загрязнённых почвах. М.: ГНУ Почвенный институт им. В.В. Докучаева Россельхозакадемии, 2009. 95 с.

8. Ильин В.Б., Сысо А.И. Микроэлементы и тяжёлые металлы в почвах и растениях Новосибирской области. Новосибирск: Изд-во СО РАН, 2001. 229 с.

9. Алексеенко В.А. Экологическая геохимия: учебник. М.: Логос, 2000. 627 с.

10. Бычинский В.А., Вашукевич Н.В. Тяжёлые металлы в почвах в зоне влияния промышленного города: учеб. пособие. Иркутск: Изд. Иркут. ун-та, 2007. $160 \mathrm{c}$.

\section{ANALYSIS OF THE ACCUMULATION AND DISTRIBUTION OF HEAVY METALS IN THE SOIL COVER OF SAMARA AND SYZRAN}

(C) 2019

Bugrov Sergey Vyacheslavovich, postgraduate student of Ecology, Botany and Nature Protection Department

Makarova Yulia Vladimirovna, candidate of biological sciences, associate professor of Ecology, Botany and Nature Protection Department

Prokhorova Nataliya Vladimirovna, doctor of biological sciences, professor of Ecology, Botany and Nature Protection Department

Platonov Igor Artemyevich, doctor of technical sciences, professor, head of Chemistry Department Goryunov Maksim Glebovich, candidate of chemical sciences, engineer of Chemistry Department Samara National Research University (Samara, Russian Federation)

\footnotetext{
Abstract. The paper presents the results of a statistical analysis of the data on the accumulation and distribution of a number of heavy metals $(\mathrm{Cr}, \mathrm{Ni}, \mathrm{Cu}, \mathrm{Pb}, \mathrm{Cd}, \mathrm{Zn})$ in the soils of the cities of Samara and Syzran in the Samara Region, carried out using the Spearman's rank correlation coefficient, the Kruskal-Wallis one-way analysis of variance and principal component analysis. The authors show that the soils of Samara are more susceptible to the accumulation of $\mathrm{Cr}, \mathrm{Ni}, \mathrm{Cu}$ and $\mathrm{Cd}$ than the soils of Syzran. Higher gross concentrations of metals are observed in the functional zones of the cities characterized by increased technogenic load - near industrial enterprises and along railways. The fixation of metals in the upper humus horizon is facilitated by the organic matter of the soil. The exception is $\mathrm{Pb}$, whose total concentration does not depend on the type of functional zone and the content of organic carbon. The Kruskal-Wallis one-way analysis of variance made it possible to establish the presence of a statistically significant relationship between the mechanical composition of the soil and the gross concentrations of $\mathrm{Cr}$ and $\mathrm{Ni}$, the content of which increases in soils of heavier texture. According to the principal component analysis, natural and technogenic sources of metals have a decisive influence on the content and distribution of heavy metals in the soil cover of the cities; soil characteristics (mechanical composition, actual acidity of the soil solution, organic carbon content) and the intensity of exposure to sources of heavy metals play a less significant role.

Keywords: soil; soil texture; actual acidity of soil solution; organic carbon content; humusness; heavy metals; gross heavy metals content; clark of chemical element; statistical methods of analysis; Spearman's rank correlation coefficient; Kruskal-Wallis one-way analysis of variance; principal component analysis; Samara; Syzran; Samara Region.
} 